EPJ Web of Conferences 45, 01001 (2013)

DOI: $10.1051 /$ epjconf/20134501001

(c) Owned by the authors, published by EDP Sciences, 2013

\title{
Check Accuracy of Oscillation Frequency of Flow inside a Cavity
}

\author{
P. Kryštůfek ${ }^{1, a}$, M. Petř́ková ${ }^{1, b}$
}

${ }^{1}$ Technical University of Liberec, Faculty of Mechanical Engineering, Department of Power Engineering Equipment, Studentska 2, Liberec 1, Czech Republic

\begin{abstract}
The article deals with check accuracy of oscillation frequency of flow by newly developed sensor and follows the previous simulations and experiments [1]. The measurement was effected during experiment on hydrodynamic table for visualization of flow [2]. Numerical verification was created by CFD program ANSYS Fluent R14 and is the main focus of this article.
\end{abstract}

\section{Introduction}

The experiment group in hydrodynamic table consists of feeding channel and vessel. The set is unsymmetrical, axes of channel and vessel are parallel, but they are displaced - see below figure 1 . The water flows in by channel of constant space and filling-up the vessel. The energy of influent waters is accumulating inside of the vessel. After explicit limit violation the vessel empties. Simultaneously to decrease waters in the vessel will get to reduction of energy (respectively pressure) in the vessel thereby to change of flow direction. The vessel begins again fill and whole process starts to repeat.

The geometry of experiment setting is defined by dimensions: the dimensions are in direction perpendicular to direction of flow constant and the dimensions are in direction of flow variable. These models were tested for different flow quantities, respectively for various velocities in inflow.

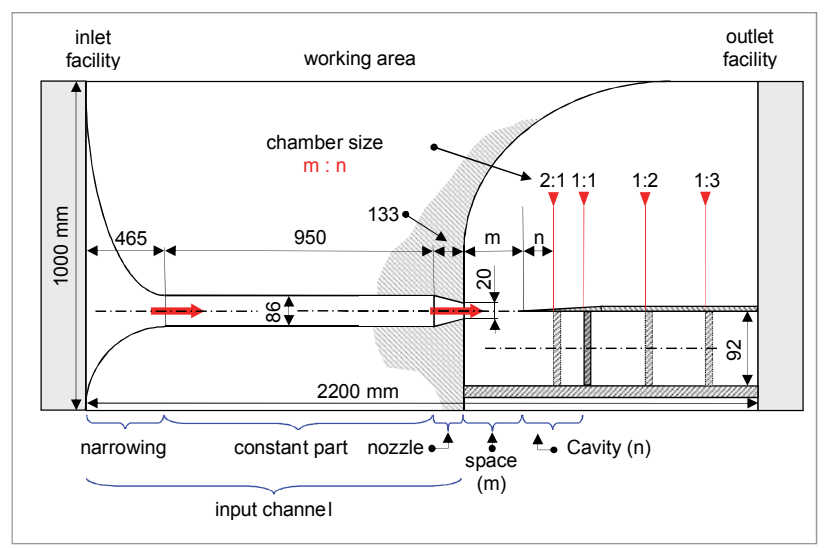

Fig. 1. Scheme of the experiment arrangement.

\footnotetext{
a e-mail: pavel.krystufek@tul.cz

be-mail: marketa.petrikova@tul.cz
}

\section{Experiment}

The experiment layout with dimensions is given in figure 1. From the inlet chamber flows the coloredwater with the aluminium dust coating to a relative long channel, which should calm the flow and let develop the velocity profile over the whole channel width. After that follows a narrowing into a nozzle and behind flows the stream inside the chamber or out.

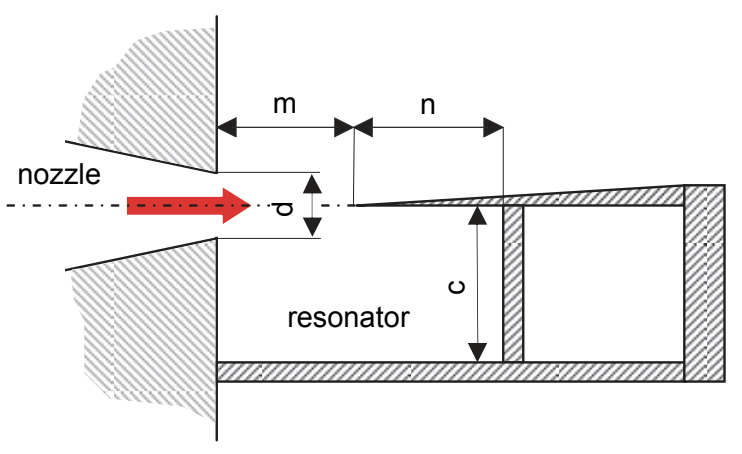

Fig. 2. Sketch of the most important geometrical dimensions.

The most significant geometric dimensions are depicted at Fig.2. Dimension $\mathbf{m}$ is the distance between the nozzle outlet and the upper corner of the resonator, there were set two positions for the collection of measurements 70 or $140 \mathrm{~mm}$. Dimension $\mathbf{n}$ is the deepness of the resonator chamber from the upper corner. This value was chosen in four ratios $2: 1,1: 1,1: 2,1: 3$ to the dimension $\mathbf{m}$. That means the values depicted in Fig.1. $\mathbf{c}$ is the width of the resonator and it is constant for all experiments, $92 \mathrm{~mm}$. d is the width of the nozzle it is $20 \mathrm{~mm}$ for all experiments. The part over the resonator is designed best as possible for simulating the outlet to free air. From this part flows 
the fluid to the outlet chamber. The last thing which was influenced was the volume flow which varies from 100 to 600 liters per hour with a step of 100 .

\section{Numerical experiment}

\subsection{Geometry}

The model of real geometry is shown on figure 3 . The detail of cavity is shown on figure 4 .

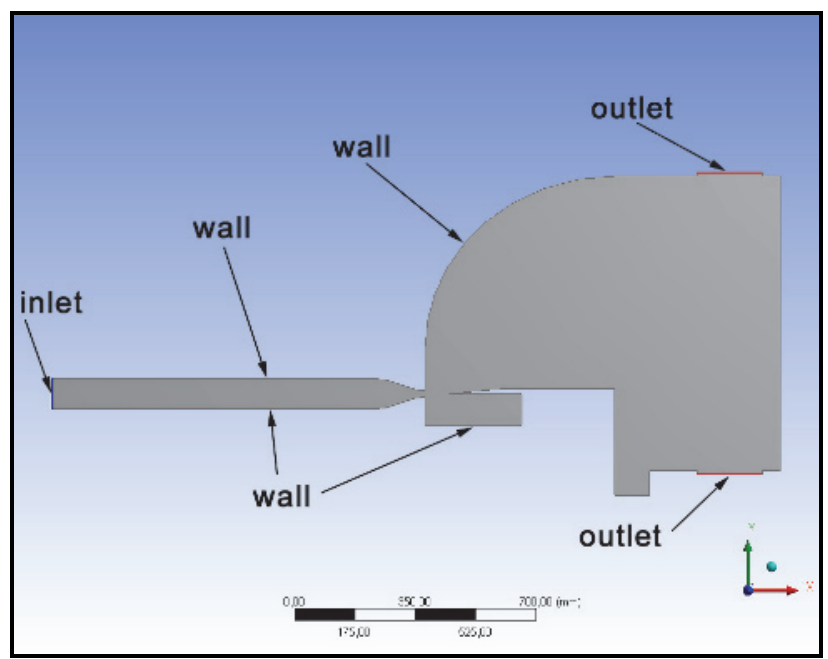

Fig. 3. Geometry from Design Modeler ${ }^{\mathrm{TM}}$.

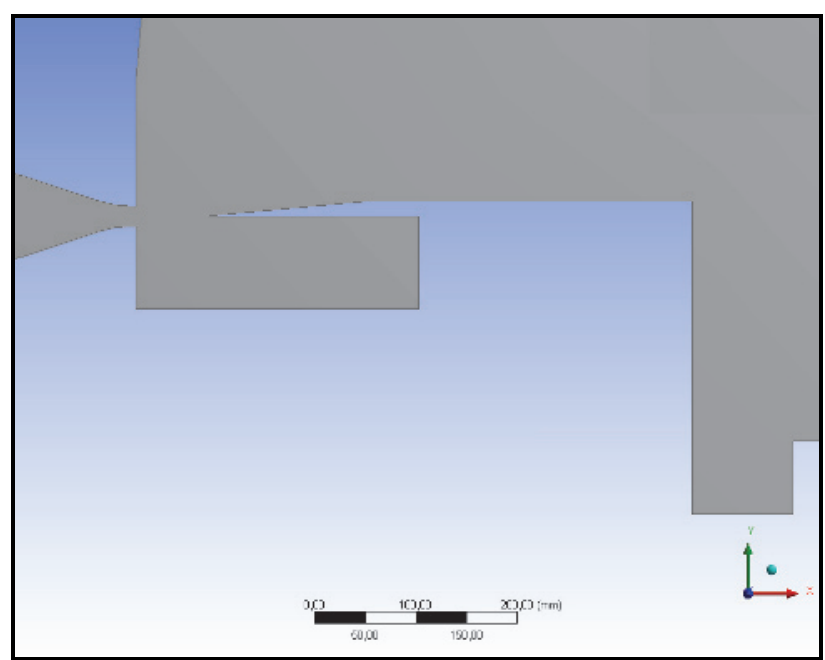

Fig. 4. Detail of cavity geometry from Design Modeler ${ }^{\mathrm{TM}}$.

\subsection{Computational grid}

The grid of the model was generated in ANSYS Meshing ${ }^{\text {TM. }}$. The combination of triangular and rectangular elements was used. The final grid had 95000 elements; the grid in outlet part is shown in figure 5 . The detail of cavity grid is shown in figure 6 .

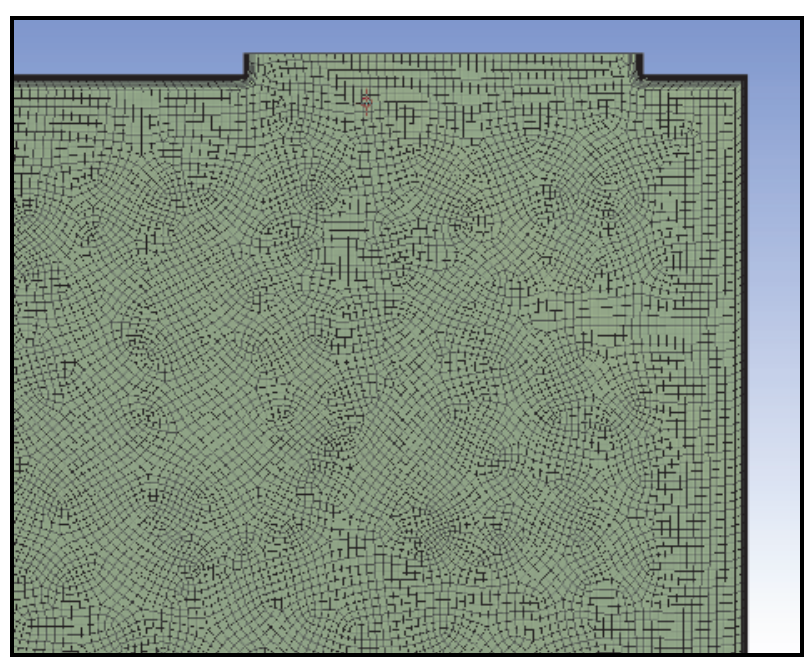

Fig. 5. The grid in outlet part from Design Meshing ${ }^{\text {TM }}$.

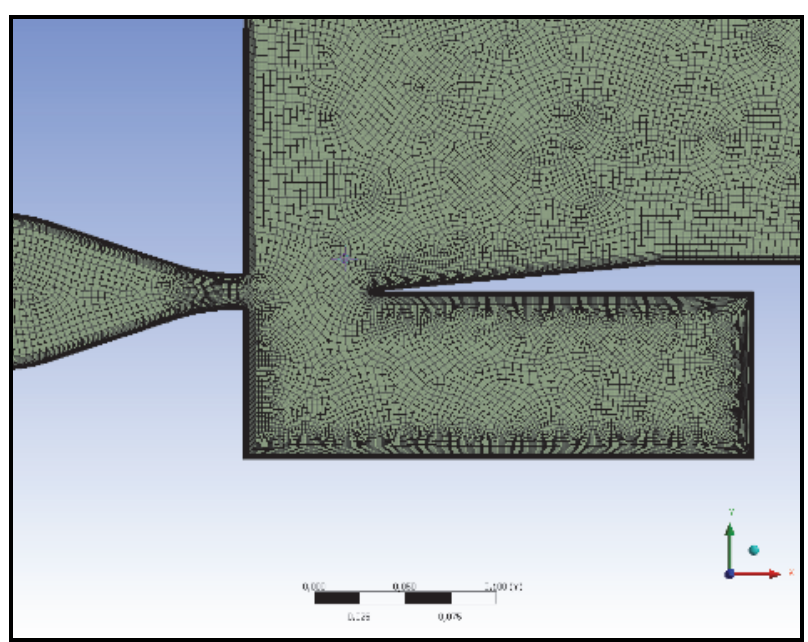

Fig. 6. Detail of cavity geometry from Design Meshing ${ }^{\text {TM }}$.

\subsection{Model setting}

Transient viscous incompressible $\mathrm{k}-\omega$ model with SST modification was used for the simulation. Six velocities $0.0389 \mathrm{~ms}^{-1}, 0.0778 \mathrm{~ms}^{-1}, 0.1167 \mathrm{~ms}^{-1}, 0.1457 \mathrm{~ms}^{-1}$, $0.1946 \mathrm{~ms}^{-1}, 0.2335 \mathrm{~ms}^{-1}$ (this corresponds to the volume flow 100, 200, 300, 400, 500 and 600 liters per hour) were set at inlet by boundary condition ,velocity-inlet”. Output boundary condition was set at ,pressure-outlet“". The boundary condition „Wall” was applied to the walls. The time step was set at value $0.001 \mathrm{~s}$. Maximum number of 500 iterations was set for one time step. It was detected, during the calculation, that the value of 15 iterations would be sufficient. The convergence condition was set to $10^{-4}$ for all monitored quantities. In this article simulated the chamber size in ratio $\mathbf{1 : 3}$ for $\mathbf{m}=70 \mathrm{~mm}$. We calculated 20000 iterations for each velocity. The $20 \mathrm{~s}$ for each velocity was simulated. Each simulation were required approximately $24 \mathrm{~GB}$ of data.

\section{Results}

First part of results shows the numerical results for the volume of flow 100, 400 and 600 liters per hour. 


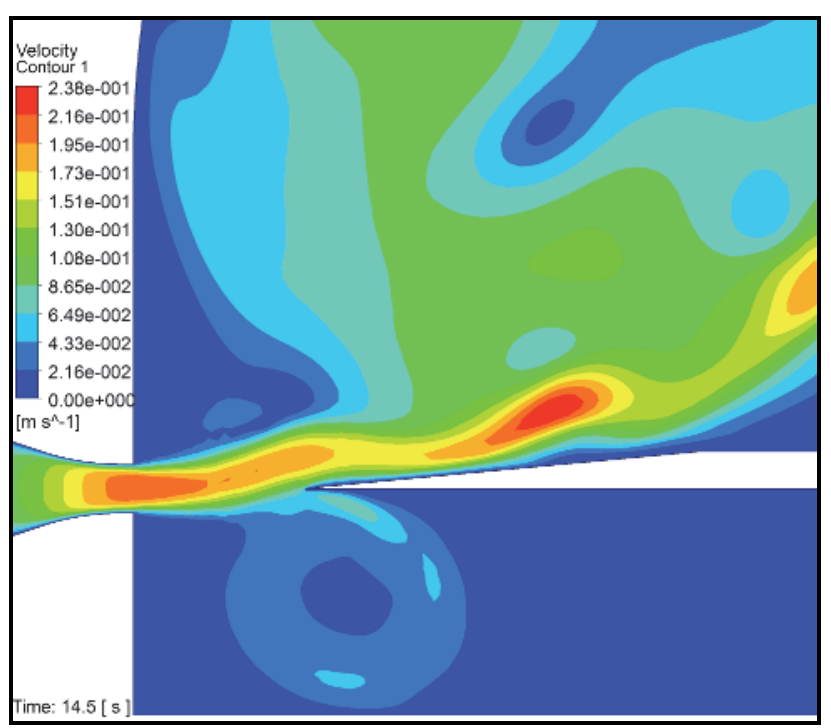

Fig. 7. Numerical results with the unsteady SST k- $\omega$

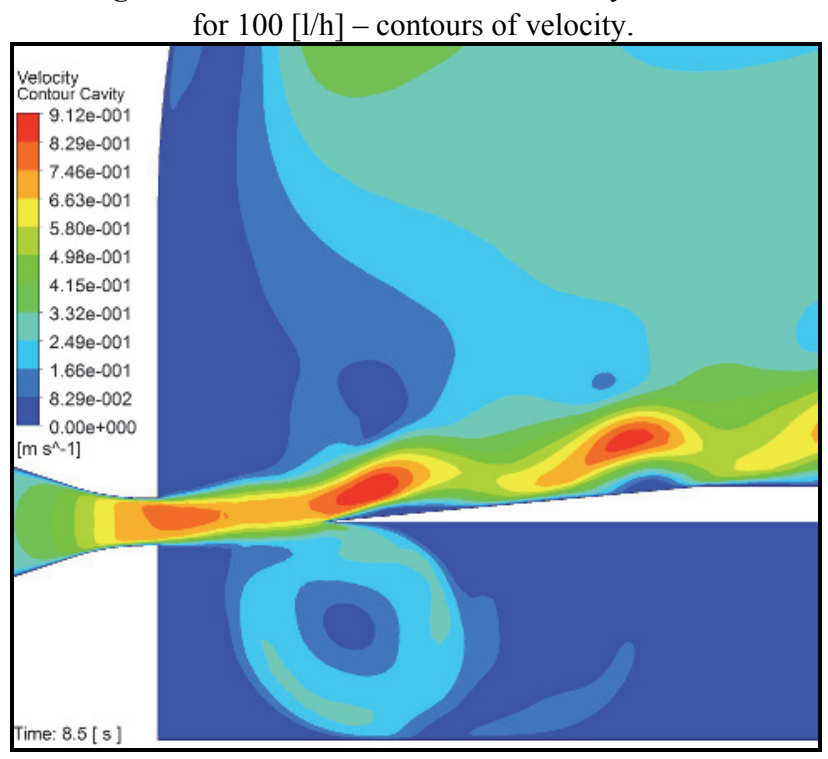

Fig. 8. Numerical results with the unsteady SST k- $\omega$ for $400[1 / \mathrm{h}]$ - contours of velocity.

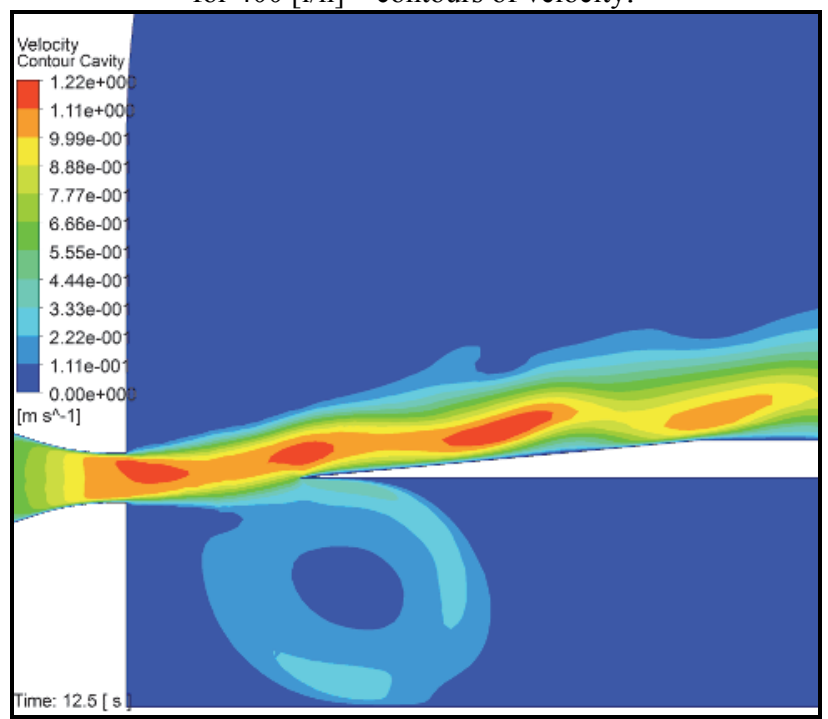

Fig. 9. Numerical results with the unsteady SST k- $\omega$ for $600[1 / \mathrm{h}]$ - contours of velocity.

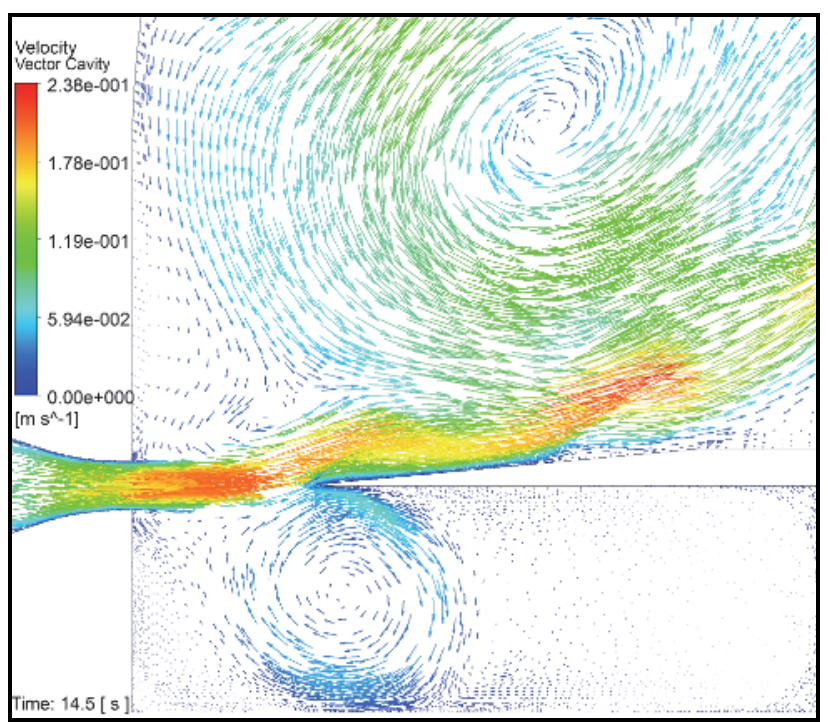

Fig. 10. Numerical results with the unsteady SST k- $\omega$

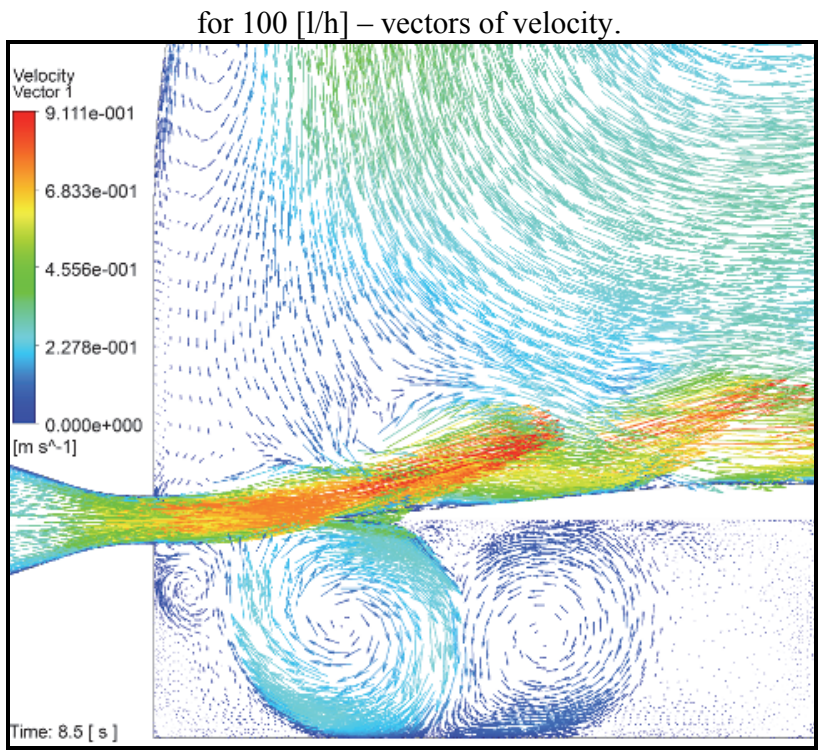

Fig. 11. Numerical results with the unsteady SST k- $\omega$ for $400[1 / \mathrm{h}]-$ vectors of velocity.

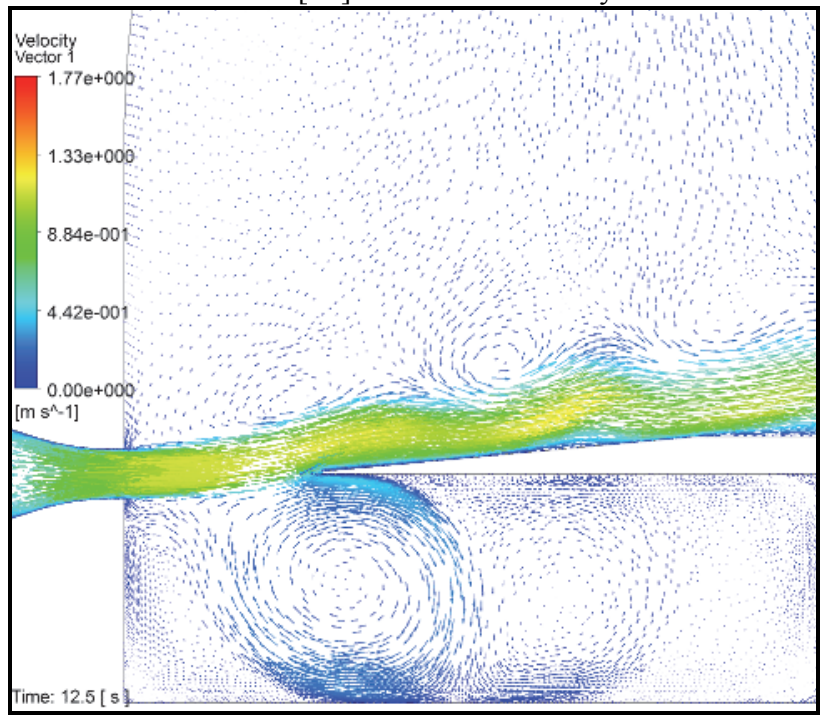

Fig. 12. Numerical results with the unsteady SST k- $\omega$ for $600[1 / \mathrm{h}]$ - vectors of velocity. 


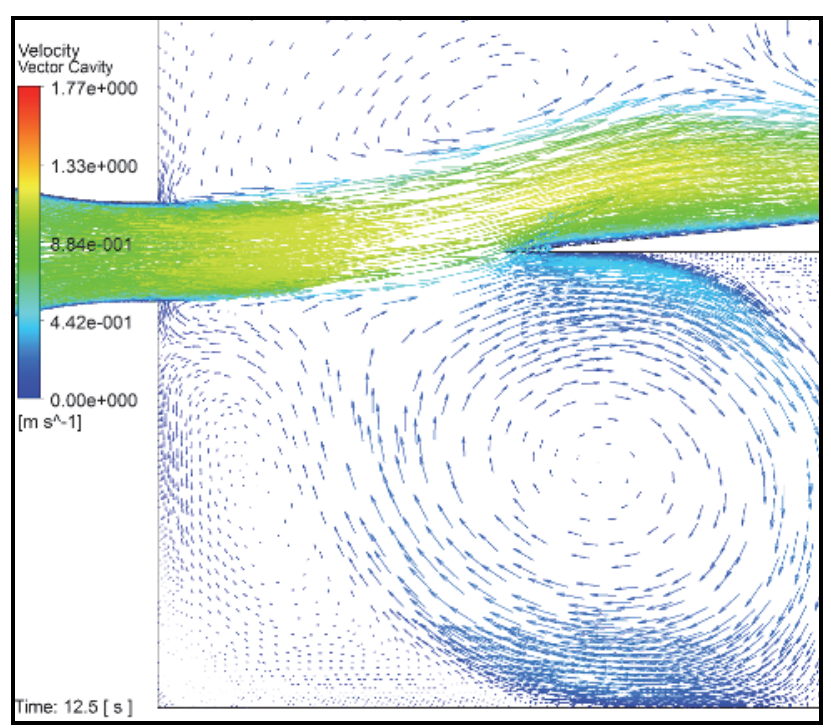

Fig. 13. Details of numerical results with the unsteady SST k- $\omega$ for $600[1 / \mathrm{h}]$ near an output of a nozzle - vectors of velocity.

Table 1. Strouhal's number Sh [-] from experiment and numerical simulations for $\mathrm{m}=70[\mathrm{~mm}]$.

\begin{tabular}{|c|c|c|}
\hline $\begin{array}{c}\text { volume flow } \\
{[\mathbf{l} / \mathbf{h}]}\end{array}$ & $\begin{array}{c}\text { Sh [-] } \\
\text { experiment }\end{array}$ & $\begin{array}{c}\text { Sh [-] } \\
\text { numerical } \\
\text { simulation }\end{array}$ \\
\hline 100 & 0.959616 & 0.993768 \\
\hline 200 & 0.394128 & 0.383850 \\
\hline 300 & 0.445530 & 0.406178 \\
\hline 400 & 0.357000 & 0.342723 \\
\hline 500 & 0.297024 & 0.281201 \\
\hline 600 & 0.257040 & 0.250773 \\
\hline
\end{tabular}

On figures 7-12 are shown numerical results from ANSYS Fluent R14. On figure 13 are shown detail of numerical results near an output of a nozzle. On table 1 are presented the frequency of oscillations from numerical simulations and from experimental [3]. The Strouhal's number Sh [-] is defined as:

$$
S h=\frac{(m+n) \cdot f}{w}
$$

where $m+n$ is the upper mentioned characteristic dimension, $f$ the oscillation frequency and $w$ the inlet velocity.

\section{Conclusions}

For this simulations were adjusted the ends outlet parts from last simulations [1] because at the given state some simplifications could have influenced the simulation so that some that some divergence to the experiment occurred. For $\mathrm{m}=70 \mathrm{~mm}$, ratio $\mathrm{m}: \mathrm{n}=1: 3$, the volume flow 100, 200, 300, 400, 500 and 600 liters per hours was created numerical simulations.

Strouhal's numbers calculated from numerical simulations are in very good agreement with experiment. For the future simulations should be the build of a 3D mesh with a phase boundary (VOF), which better suits the experiment. Also, can then be surface height measured.

\section{Acknowledgements}

This work was financially supported by the particular research student grant SGS 2823 at TU of Liberec.

\section{References}

1. M. Petříková, P. Peukert, P. Kryštůfek, KOD, 439444 (2012)

2. M. Petř́iková, Experimental fluid mechanics (2007)

3. M. Petř́k ová, P. Kryštůfek, J. Unger, Experimental fluid mechanics, 278-284 (2009)

4. F. M. White, Fluid Mechanics - Fourth Edition (2001)

5. Ansys Inc., Documentation for ANSYS Fluent R14 (2012)

6. M. Petř́́ková, P. Kryštůfek, J. Kneř, Mechanical engineering (2007)

7. M. Petříková, P. Kryštůfek, Mechanical engineering (2008) 